Research Article

\title{
Slip Effects on Unsteady Oblique Stagnation Point Flow of Nanofluid in a View of Inclined Magnetic Field
}

\author{
Rizwana Rizwana, ${ }^{1}$ Azad Hussain $\left(D,{ }^{1}\right.$ and S. Nadeem ${ }^{2,3}$ \\ ${ }^{1}$ Department of Mathematics, University of Gujrat, Gujrat, Pakistan \\ ${ }^{2}$ Mathematics and its Applications in Life Sciences Research Group, Ton Duc Thang, University, Ho Chi Minh City, Vietnam \\ ${ }^{3}$ Faculty of Mathematics and Statistics, Ton Duc Thang University, Ho Chi Minh City, Vietnam
}

Correspondence should be addressed to Azad Hussain; azad.hussain@uog.edu.pk

Received 31 May 2020; Accepted 6 August 2020; Published 27 September 2020

Academic Editor: Mostafa S. Shadloo

Copyright (C) 2020 Rizwana Rizwana et al. This is an open access article distributed under the Creative Commons Attribution License, which permits unrestricted use, distribution, and reproduction in any medium, provided the original work is properly cited.

\begin{abstract}
This study may be applicable in heavy power engine and cooling of a nuclear reactor, insulation for buildings, petroleum reservoir operations, and magnetic material processing solar energy collectors. In this manuscript, the slip results are evaluated for the nonNewtonian fluid on the oblique stagnation point flow of induced magnetic field over the oscillating surface. The valuation of heat flux is examined through the Fourier law of heat transfer. The metallic nanoparticle Copper $(\mathrm{Cu})$ is within the base fluid, and water is utilized in the analysis. Nanofluids have benefits such as steadiness of the working fluid, decreasing blockage, clogs, decreasing prices, decreasing the friction coefficient, and decreasing the size of the heat transfer system. Similarity variables are utilized to convert the developed flow into higher nonlinear coupled ordinary differential equations (ODE) which are tackled numerically using a mathematical technique such as the bvp4c method in Maple and Matlab software. According to the present geometry, the flow behavior of the operating nanofluid has analyzed by stream lines. Disparities in velocity and temperature profile are demonstrated by graphs to describe the effects of controlling parameters. The Casson fluid parameter enhances the velocity of the fluid. The system heats up by the impact of Joule heating and dissipation.
\end{abstract}

\section{Introduction}

Due to the small size of the nanoparticles, these fluids behave like normal fluids first introduced by Choi and Eastman [1]. Nanofluids are essentially utilized to improve heat conduction and have many applications in several business processes such as heat exchanger equipment and electronic cooling system radiators given by Khan et al. [2]. Due to narrative properties of nanofluids, it is potentially valuable in numerous applications in heat transfer, such as car engines, microelectronics, engine cooling/vehicle thermal management, chiller, nuclear reactor, heat exchanger, domestic refrigerator, fuel cells, pharmaceutical processes, coolant, in grinding, defense, in boiler flue gas temperature decline, in space technology, machining, and ship given by Turkyilmazoglu [3]. Nanofluids have benefits such as steadiness of the working fluid, decreasing blockage, clogs, decreasing prices, decreasing the friction coefficient, decreasing the size of the heat transfer system, improving steadiness related to other colloids, decreasing the power required for fluid pumping, increasing heat transfer capability, and improving the heat transfer. Several researchers have studied the nanofluid flow [4-13].

Hiemenz [14] was the first person who studied the stagnation point flow by finding the exact solution to the Navier-Stokes equations. Stagnation point flows can be unsteady or steady, inviscid or viscous, oblique or normal, two or more dimensional, and opposite or onward. Alike flow frequently compacts with the motion of fluid close to the stagnation region of a firm surface preserved in moving fluid given by Khan et al. [15]. Stagnation point flows beside the heat transfer characteristic are fairly manifested in rotating filaments, paper manufacture, melt spinning process, crystal puffing, and continuous molding given by Abbas 
et al. [16]. A great number of researchers have put their attention on stagnation point flows [17-26].

Non-Newtonian fluids have a huge range of industrial applications, such as high molecular weight systems, most multiphase mixtures, foods, and solutions. When air is involved in such procedures as agitation, mixing, dispersion, and kneading, then gas bubbles are isolated and assorted in fluids given by Zhan et al. [27]. Materials displaying nonNewtonian flow characteristics include natural products, food products, magmas and lavas, biological fluids, dairy wastes, and agricultural wastes, building materials, soap solutions, polymer melts and solutions, multiphase mixtures, and personal care products including cosmetics and toiletries, given by Ijaz et al. [28]. Non-Newtonian fluids are of excessive importance in engineering sciences, medical field, and industry. The increasing applications of nonNewtonian fluids are in demonstrating of extrusion of polymers, steel substances, petroleum drilling, and blasting of glasses. Few polymers are utilized in communication appliances, medical, and agriculture given by Hussain et al. [29]. Many researchers have studied the non- Newtonian fluid flows [30-40].
In the present study, we describe the non-Newtonian fluid for oblique stagnation point flow with the induced magnetic field of nanofluid over the oscillatory and slip surface. Heat transfer is exposed to $\mathrm{Cu}$ nanoparticles. The coupled differential equations are solved by mathematical techniques such as bvp4c in MatLab and Maple. Graphical results are achieved for velocity and temperature profiles. Moreover, the flow behavior is also demonstrated by streamlines.

\section{Formulation}

Assume the two-phase flow model for oscillatory, unsteady, and incompressible two-dimensional state flow. The slip results are evaluated for the non-Newtonian fluid on the oblique stagnation point flow of induced magnetic field over the oscillating surface. The stream of nanofluid occupies obliquely on a plate vacillates in its own plan. The fluid is $y \geq 0$, the upper half of the plane. The flow equations are given as

$$
\begin{aligned}
\frac{\partial u}{\partial x}+\frac{\partial v}{\partial y}= & 0 \\
\frac{\partial \bar{u}}{\partial t}+\bar{u} \frac{\partial \bar{u}}{\partial \bar{x}}+\bar{v} \frac{\partial \bar{u}}{\partial \bar{y}}= & -\frac{1}{\rho} \frac{d p}{d \bar{x}}+v_{n f}\left(1+\frac{1}{\beta}\right)\left(\frac{\partial^{2} \bar{u}}{\partial \bar{x}^{2}}+\frac{\partial^{2} \bar{v}}{\partial \bar{y}^{2}}\right) \\
& -4 a^{2} \frac{\sigma_{n f}}{\rho_{n f}} \frac{\beta_{o}^{2}}{4 a^{2}+b^{2}} \bar{u}, \\
\frac{\partial \bar{v}}{\partial t}+\bar{u} \frac{\partial \bar{v}}{\partial \bar{x}}+\bar{v} \frac{\partial \bar{v}}{\partial \bar{y}}= & -\frac{1}{\rho} \frac{d p}{d \bar{y}}+v_{n f}\left(1+\frac{1}{\beta}\right)\left(\frac{\partial^{2} \bar{u}}{\partial \bar{x}^{2}}+\frac{\partial^{2} \bar{v}}{\partial \bar{y}^{2}}\right) \\
& -4 a^{2} \frac{\sigma_{n f}}{\rho_{n f}} \frac{\beta_{o}^{2}}{4 a^{2}+b^{2}} \bar{v}, \\
\alpha_{n f}\left(\frac{\partial^{2} T}{\partial \bar{x}^{2}}+\frac{\partial^{2} T}{\partial \bar{y}^{2}}\right)= & \frac{\partial T}{\partial t}+\bar{u} \frac{\partial T}{\partial \bar{x}}+\bar{v} \frac{\partial T}{\partial \bar{y}},
\end{aligned}
$$

with boundary conditions

$$
\begin{aligned}
& \bar{u}=U \cos \omega \bar{t}+\lambda_{1} \frac{\mu_{n f}}{\mu_{f}} \frac{\partial \bar{u}}{\partial \bar{y}}, \quad \bar{v}=0, \\
& \bar{T}=\bar{T}_{w}+\varepsilon\left(\bar{T}_{w}-\bar{T}_{\infty}\right) \operatorname{Re}\left[e^{i \omega \bar{t}}\right]+\lambda_{2} \frac{k_{n f}}{k_{f}} \frac{\partial \bar{T}}{\partial \bar{y}}, \quad \bar{y}=0, \\
& \bar{u}=a \gamma \bar{y}+\bar{x}, \\
& \bar{v}=-a \bar{y}, \quad \bar{y} \longrightarrow \infty,
\end{aligned}
$$

where $\quad \rho_{n f}, B_{0}, \gamma_{n f}, \alpha_{n f}, v_{n f}, \mu_{n f}, \lambda_{1}, \lambda_{2}, \bar{p}=\bar{p}(\bar{x}, \bar{y}, \bar{t})$, and $\bar{V}=(\bar{u}(\bar{x}, \bar{y}, \bar{t}), \bar{v}(\bar{x}, \bar{y}, \bar{t}), 0)$ are the density of nanofluid, magnetic field, thermal diffusivity of nanofluid, kinematic viscosity, dynamic viscosity, slip parameters, velocity field, and pressure, respectively.

Suppose fluid obliquely affects via the plane $\bar{y}=A$ and the velocity components are

$$
\begin{aligned}
& \bar{u}=a \bar{x}+b(\bar{y}-B), \\
& \bar{v}=-a(\bar{y}-A), \quad A, B \text { Parameters. }
\end{aligned}
$$

Now, the stagnation point develops $(A, b / a(B-A))$, and the streamlines are hyperbolas whose asymptotes are

$$
\bar{y}=-\frac{2 a}{b} \bar{x}-A+2 B, \quad \bar{y}=A \text {. }
$$

Moreover, the magnetic field must be equivalent to distributing streamline due to presence of oblique stagnation flow as 


$$
\bar{H}_{0}=\frac{B_{0}}{\sqrt{4 a^{2}+b^{2}}}(-b \widehat{i}+2 a \widehat{j}),
$$

where $B_{0}$ is the uniform magnetic field and $a$ and $b$ are constants.

Consider the velocity component as

$$
\begin{aligned}
& \bar{u}=a x \bar{f}^{\prime}(\bar{y})+b \bar{g}(\bar{y}), \\
& \bar{v}=-a \bar{f}(\bar{y}) .
\end{aligned}
$$

The streamlines' flow becomes hyperbolic nature when considering oblique stagnation flow, and their asymptotes may have the equation

$$
\begin{aligned}
& \bar{y}=0, \\
& \bar{y}=-\frac{2 a}{b} \bar{x} .
\end{aligned}
$$

The boundary conditions are given by

$$
\begin{aligned}
\bar{f}(0) & =0, \bar{f}^{\prime}(0)=\lambda_{1} \frac{\mu_{n f}}{\mu_{f}} \bar{f}^{\prime \prime}(0), \\
\bar{g}(0, \bar{t}) & =\operatorname{Re}\left[\frac{U}{b} e^{i \omega \bar{t}}\right]+\lambda_{1} \frac{\mu_{n f}}{\mu_{f}} \bar{g}^{\prime}(0, \bar{t}), \\
\bar{f}^{\prime}(\bar{y}) & =1, \\
\bar{g}^{\prime(\bar{y}, \bar{t})} & =1, \quad \bar{y} \longrightarrow \infty .
\end{aligned}
$$

From (12), the behavior of $\bar{f}$ and $\bar{g}$ asymptotically at infinity is given by

$$
\begin{aligned}
& \bar{f} \sim \bar{y}-A, \\
& \bar{g} \sim \bar{y}-B, \quad \bar{y} \longrightarrow \infty .
\end{aligned}
$$

The continuity equation (1) deduces the existence of a stream function $\psi$ such that

$$
\begin{aligned}
& u=\frac{\partial \psi}{\partial \bar{y}}, \\
& v=-\frac{\partial \psi}{\partial \bar{x}} .
\end{aligned}
$$

Applying equation (14) in (2) to (4), eliminating the pressure using this $p_{x y}=p_{y x}$ yields, also making use of equation (10) in system (2) to (4), and using boundary conditions (11) and (12), in equations (14) to (17), we obtain

$$
\begin{gathered}
\frac{1}{a} v_{n f}\left(1+\frac{1}{\beta}\right)\left(\frac{d^{3} \bar{f}}{d \bar{y}^{3}}\right)+\bar{f} \frac{d^{2} \bar{f}}{d \bar{y}^{2}}-\frac{d \bar{f}}{d \bar{y}} \frac{d \bar{f}}{d \bar{y}} \\
-4 a^{2} \frac{\sigma_{n f}}{\rho_{n f}} \frac{\beta_{o}^{2}}{4 a^{2}+b^{2}}=-4 a^{2} \frac{\sigma_{n f}}{\rho_{n f}} \frac{\beta_{o}^{2}}{4 a^{2}+b^{2}}-1, \\
+4 a^{2} \frac{1}{{ }^{2} \frac{\sigma_{n f}}{\rho_{n f}}} \frac{\beta_{o}^{2}}{4 a^{2}+b^{2}}\left(1+\frac{1}{\beta}\right)\left(\frac{\partial^{2} \bar{g}}{\partial \bar{y}^{2}}\right)+f \frac{\partial \bar{g}}{\partial \bar{y}}-\frac{\partial \bar{g}}{\partial \bar{y}} \frac{d \bar{f}}{d \bar{y}}-\frac{\partial \bar{g}}{\partial \bar{t}} \\
\end{gathered}
$$

We define

$$
\begin{aligned}
f(\bar{y}) & =\sqrt{\frac{V_{f}}{k}} F(y), \\
g(\bar{t}, \bar{y}) & =\frac{V_{f}}{k}\left[G_{o}(y)+\varepsilon G_{1}(y) e^{i \tau}\right], \\
y & =\sqrt{\frac{k}{V_{f}} \bar{y}}, \\
\Omega & =\frac{w}{k}, \\
\tau & =w t \\
\varepsilon & =\frac{U}{\sqrt{V_{f} k}}, \\
\theta_{o}(y)+\varepsilon \theta_{1}(y) & =\frac{T-T_{\infty}}{T_{w}-T_{\infty}} .
\end{aligned}
$$

In the light of equation (21), governing equations (4), (15), and (16) become

$$
\begin{array}{r}
\left(\frac{\mu_{n f}}{\mu_{f}}\right)\left(\frac{\rho_{f}}{\rho_{n f}}\right)\left(1+\frac{1}{\beta}\right)\left(F^{\prime \prime \prime}\right)-\left(F^{\prime}\right)^{2}+F F^{\prime \prime}+1+\frac{\rho_{f}}{\rho_{n f}} M^{2}\left(1-F^{\prime}\right)=0, \\
\left(\frac{\mu_{n f}}{\mu_{f}}\right)\left(\frac{\rho_{f}}{\rho_{n f}}\right)\left(1+\frac{1}{\beta}\right)\left(G_{o}^{\prime \prime}\right)+G_{o}^{\prime} F-G_{o} F^{\prime}-\frac{\rho_{f}}{\rho_{n f}} M^{2}\left(f-G_{o}\right)-\left(1+\frac{\rho_{f}}{\rho_{n f}} M^{2}\right)(\delta-\alpha)=0, \\
\left(\frac{\mu_{n f}}{\mu_{f}}\right)\left(\frac{\rho_{f}}{\rho_{n f}}\right)\left(1+\frac{1}{\beta}\right)\left(G_{1}^{\prime \prime}\right)+G_{1}^{\prime} F-G_{1} F^{\prime}-i \Omega G_{1}^{\prime}-\frac{\rho_{f}}{\rho_{n f}} M^{2} G_{1}^{\prime}=0, \\
\frac{k_{n f}}{k_{f}} \theta_{o}^{\prime \prime}+p r \frac{\left(\rho C_{p}\right)_{S}}{\left(\rho C_{p}\right)_{f}} F \theta_{o}^{\prime}=0,
\end{array}
$$




$$
\begin{aligned}
\frac{k_{n f}}{k_{f}} \theta_{1}^{\prime \prime}+\operatorname{pr} \frac{\left(\rho C_{p}\right)_{S}}{\left(\rho C_{p}\right)_{f}} F \theta_{1}^{\prime}-i \Omega p r \frac{\left(\rho C_{p}\right)_{S}}{\left(\rho C_{p}\right)_{f}} \theta_{1} & =0, \\
f(0) & =0, \\
f^{\prime}(0) & =N_{1} \frac{\mu_{n f}}{\mu_{f}} f^{\prime \prime}(0), \\
g_{0}(0) & =N_{1} \frac{\mu_{n f}}{\mu_{f}} g_{0}^{\prime}(0), \\
g_{1}(0) & =1+N_{1} \frac{\mu_{n f}}{\mu_{f}} g_{1}^{\prime}(0), \\
\theta_{0}(0) & =1+N_{2} \frac{k_{n f}}{k_{f}} \theta_{0}^{\prime}(0), \\
\theta_{1}(0) & =1+N_{2} \frac{k_{n f}}{k_{f}} \theta_{1}^{\prime}(0), \\
\theta_{1}(y) & =0, \quad f \sim y-\alpha, g \sim y-\beta \leq \bar{y} \longrightarrow \infty .
\end{aligned}
$$

In which $\phi, \rho_{n f}, \rho_{f}, \rho_{s}, \alpha_{n f}, k_{n f}, k_{s}, k_{f}, \rho_{n f},\left(\rho C_{p}\right)_{n f}, \operatorname{Pr}$, $\Omega, M$, and $\epsilon$ symbolized for nanoparticles volume fraction, the heat capacity of nanofluid, the thermal conductivity of solid fractions fluid, thermal conductivity of nanofluid, densities of fluid and solid fractions, Prandtl number, dimensionless frequency, Hartmann number, and amplitude of the wave, respectively, which are defined as

$$
\begin{aligned}
& \mu_{n f}=\frac{\mu_{n f}}{(1-\varphi)^{2.5}\left[(1-\varphi) \rho_{f}+\varphi \rho_{s}\right]}, \\
& \alpha_{n f}=\frac{k_{n f}}{\left(\rho C_{p}\right)_{n f}} \text {, } \\
& \rho_{n f}=\varphi \rho_{s}+(1-\varphi) \rho_{f} \text {, } \\
& \frac{k_{n f}}{k_{f}}=\frac{\left(k_{s}+2 k_{f}\right)-2 \varphi\left(k_{s}-k_{f}\right)}{\left(k_{s}+2 k_{f}\right)-\varphi\left(k_{s}-k_{f}\right)}, \\
& \left(\rho C_{p}\right)_{n f}=\varphi\left(\rho C_{p}\right)_{s}+(1-\varphi)\left(\rho C_{p}\right)_{f} \text {, } \\
& \delta=\sqrt{\frac{a}{v_{f}}} B, \\
& \alpha=\sqrt{\frac{a}{v_{f}}} A, \\
& \Omega=\frac{\omega}{a}, \\
& N_{1}=\sqrt{\frac{a}{v_{f}}} \lambda_{1}, \\
& M^{2}=4 a \frac{\sigma_{f}}{\rho_{f}} \frac{B_{0}^{2}}{4 a^{2}+b^{2}}, \\
& \operatorname{Pr}=\frac{v_{f}}{k_{f}}, \\
& N_{2}=\sqrt{\frac{a}{v_{f}}} \lambda_{2} \text {. }
\end{aligned}
$$

The Skin friction number can be extolled as

$$
C_{f}=\frac{\tau_{w}}{1 / 2 \rho_{f} U_{w}^{2}}
$$

and the shear stress is declared by

$$
\tau_{w}=\left.\left[\mu_{n f} \frac{\partial \bar{u}}{\partial \bar{y}}\right]\right|_{\bar{y}=0}
$$

Nondimensional form of equation (39) takes the form

$$
\frac{1}{2} \operatorname{Re}_{\bar{x}} C_{f}=\left(\frac{\mu_{n f}}{\mu_{f}}\right) \frac{\rho_{f}}{\rho_{n f}}\left[\sqrt{\operatorname{Re}} f^{\prime \prime}(0)+\frac{b}{a}\left(g_{0}^{\prime}(0)-\varepsilon g_{1}^{\prime}(0) e^{i t}\right)\right],
$$

where $\operatorname{Re}=k x^{2} / v_{f}$ is the local Reynolds number.

The nondimensional stream function is

$$
\psi^{*}=\frac{\psi}{V_{f}}=x F(\eta)+G(\eta)
$$

Displayed in Figure 1, the fluid flow forms an angle $\alpha$ with the plate, and the slope of the straight line can be found by putting $\psi^{*}=0$ as $\psi=1 / 2 \gamma y^{2}+x y$, where $\eta=-2 / \gamma x$ which gives slope $=-2 / \gamma$. Hence, the $\gamma$ (shearing parameter) and $\alpha$ (impinging angle) relationship is

$$
\alpha=\tan ^{-1}\left(-\frac{2}{\gamma}\right)
$$

The Nusslet number $N u$ is presented as

$$
N u=\frac{x q_{w}}{k_{f}\left(T_{w}-T_{\infty}\right)},
$$

and heat flux is computed by 


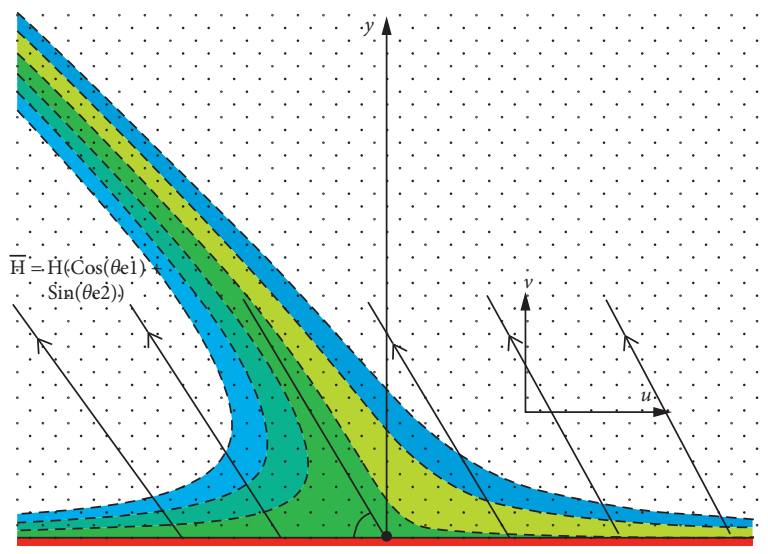

Figure 1: Geometry of the flow problem.

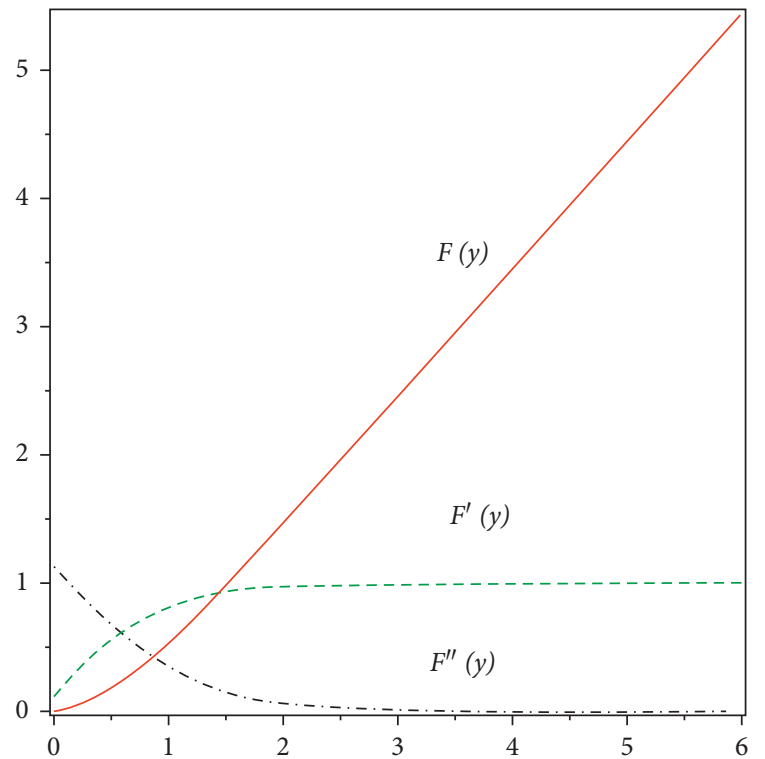

Figure 2: Exposing $F(y), F^{\prime}(y)$, and $F^{\prime \prime}(y)$ for $M=1.5, \beta=0.5$, and $\gamma=0.5$.

$$
q_{w}=-\left.k_{n f} \frac{\partial T}{\partial y}\right|_{y=0}
$$

Dimensionless form of equation (40):

$$
\left(\operatorname{Re}_{x}\right)^{-1 / 2} N u=-\frac{k_{n f}}{k_{f}}\left[\theta_{0}^{\prime}(0)+\varepsilon \theta_{1}(0) e^{i \tau}\right] .
$$

\section{Solution Process}

Numerical solution of equations (18)-(22) is achieved using BVP solution technique built in Matlab and Maple software. It can be perceived that leading classification (18)-(22) has one-way coupling, i.e., $f(y)$ effects $G_{0}(y), G_{1}(y), \theta_{0}(y)$, and $\theta_{1}(y)$ but not vice versa. Also, for minor values of $\Omega$, a

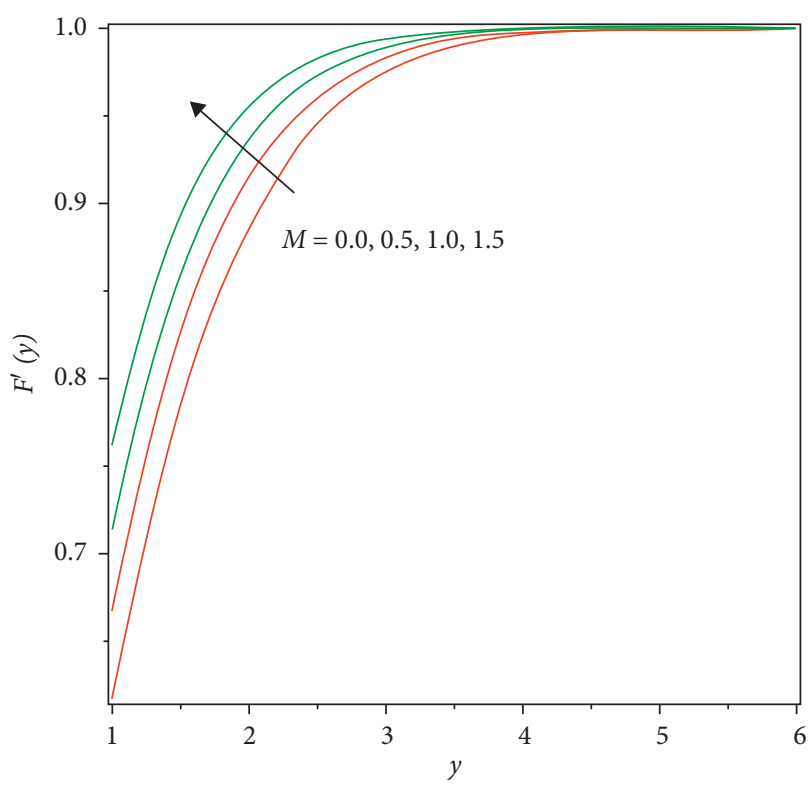

Figure 3: Influence of $M$ on $F^{\prime}$.

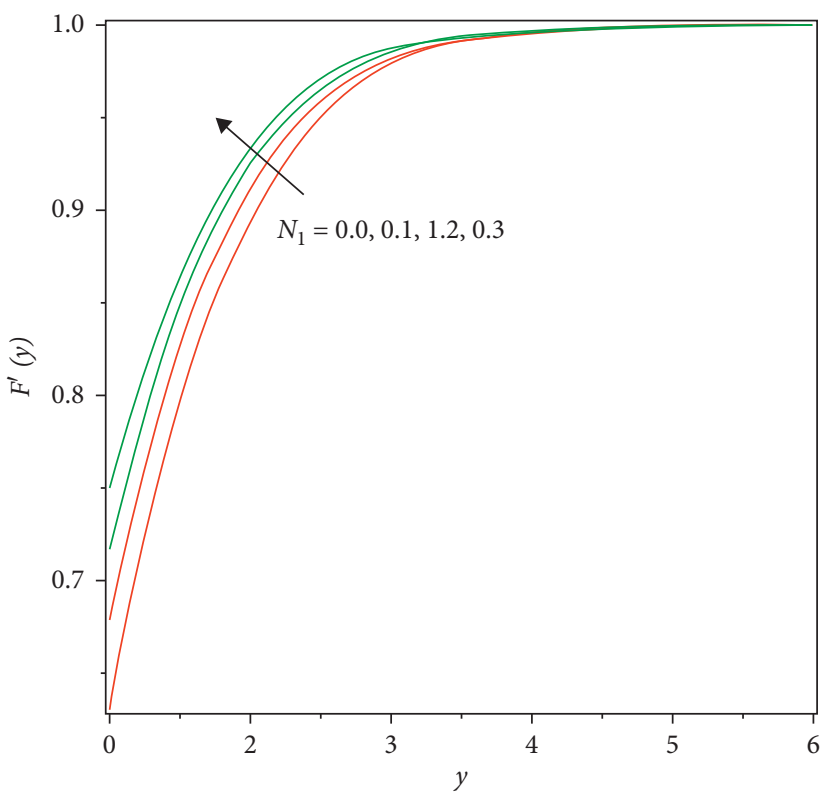

Figure 4: Variation of $N_{1}$ on $F^{\prime}$.

series solution of equations (20) and (22) has been obtained followed by

$$
\begin{aligned}
& G_{1}(y)=\sum_{n=0}^{\infty}(i \Omega)^{n} \chi_{n}(y), \\
& \theta_{1}(y)=\sum_{n=0}^{\infty}(i \Omega)^{n} \vartheta_{1 n}(y) .
\end{aligned}
$$
form

We are taking the solution of the real part only, as the 


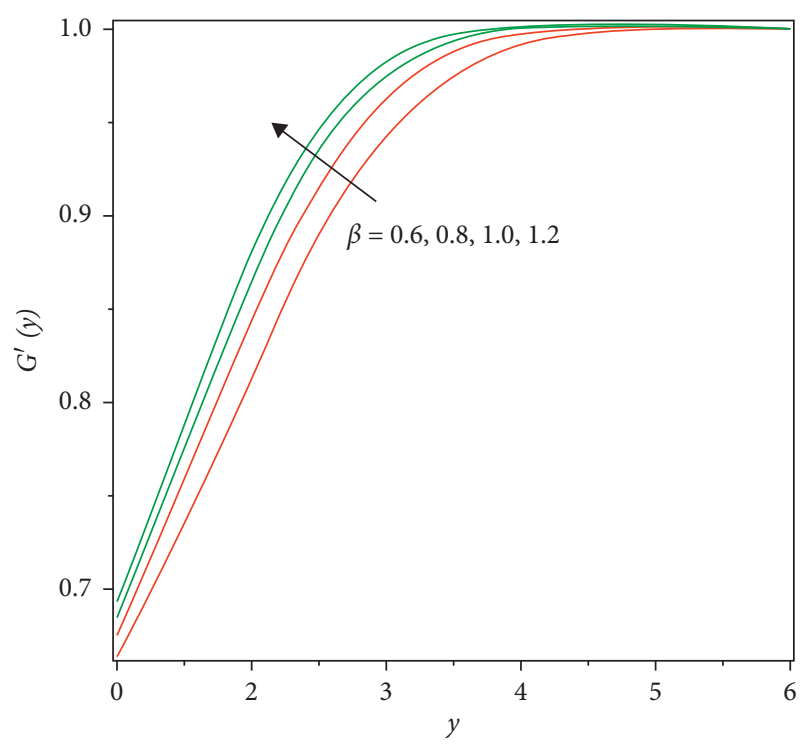

FIGURE 5: Influence of $\beta$ on velocity component $F^{\prime}$.

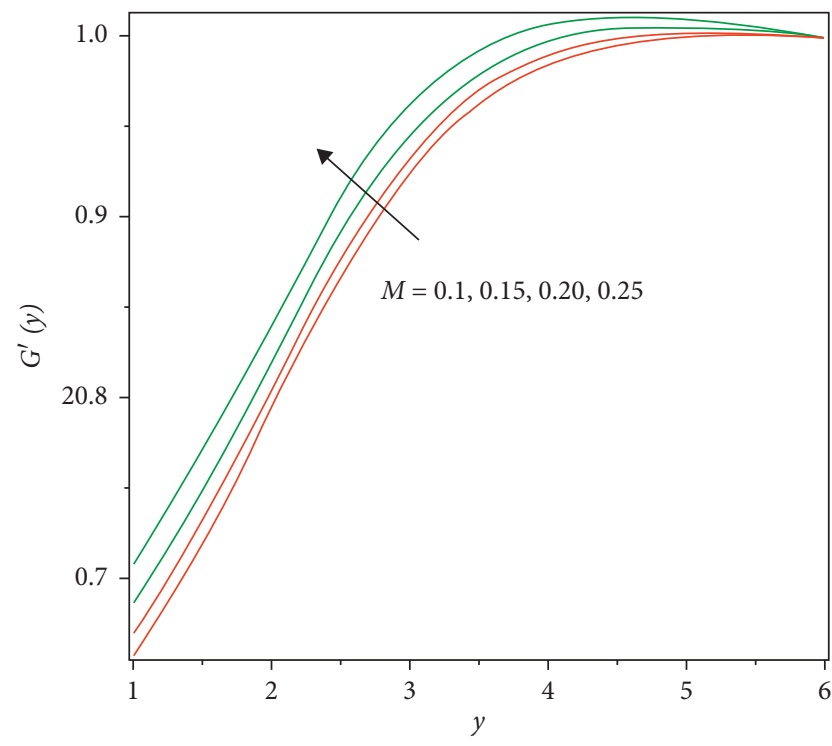

FIgURE 6: Inspiration of $M$ on velocity component $G^{\prime}$.

$$
G_{1}(y)=\chi_{0}(y)-\Omega^{2} \chi_{2}(y)+\Omega^{4} \chi_{4}(y) .
$$

Using equation (35) in equations (20) and (23), we obtain

$$
\begin{aligned}
& \left(\frac{\mu_{n f}}{\mu_{f}}\right)\left(\frac{\rho_{f}}{\rho_{n f}}\right)\left(1+\frac{1}{\beta}\right)\left(\chi_{o}^{\prime \prime}\right)+\chi_{o}^{\prime} F-\chi_{o} F^{\prime}-\frac{\rho_{f}}{\rho_{n f}} M^{2} \chi_{o}=0, \\
& \left(\frac{\mu_{n f}}{\mu_{f}}\right)\left(\frac{\rho_{f}}{\rho_{n f}}\right)\left(1+\frac{1}{\beta}\right)\left(\chi_{n}^{\prime \prime \prime}\right)+\chi_{n}^{\prime \prime} F-\chi_{n}^{\prime} F^{\prime}-\frac{\rho_{f}}{\rho_{n f}} M^{2} \chi_{o}=\chi_{n-1},
\end{aligned}
$$

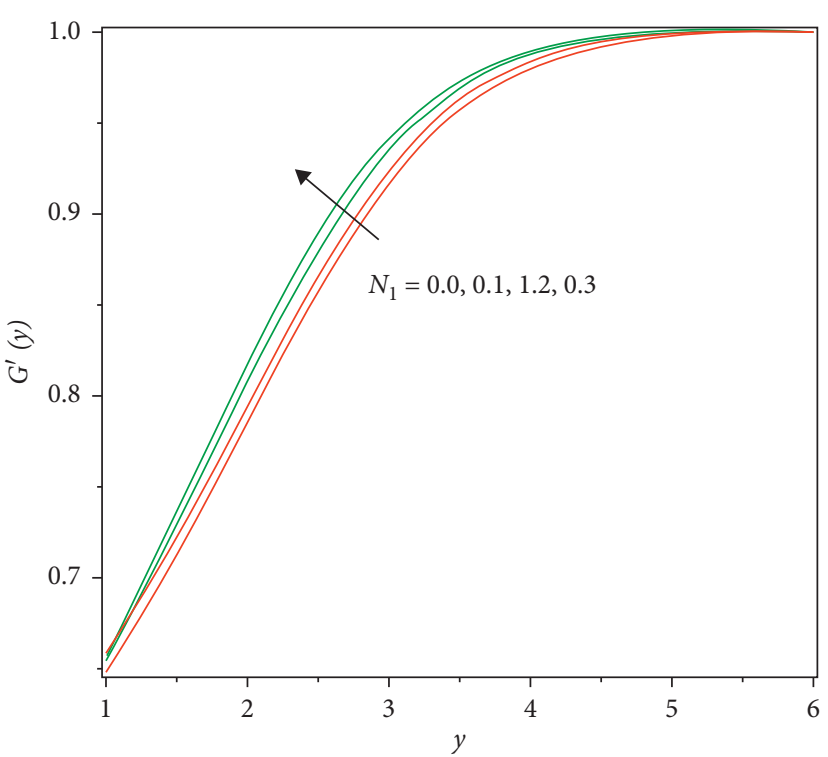

Figure 7: Result of $N_{1}$ on $G^{\prime}(y)$.

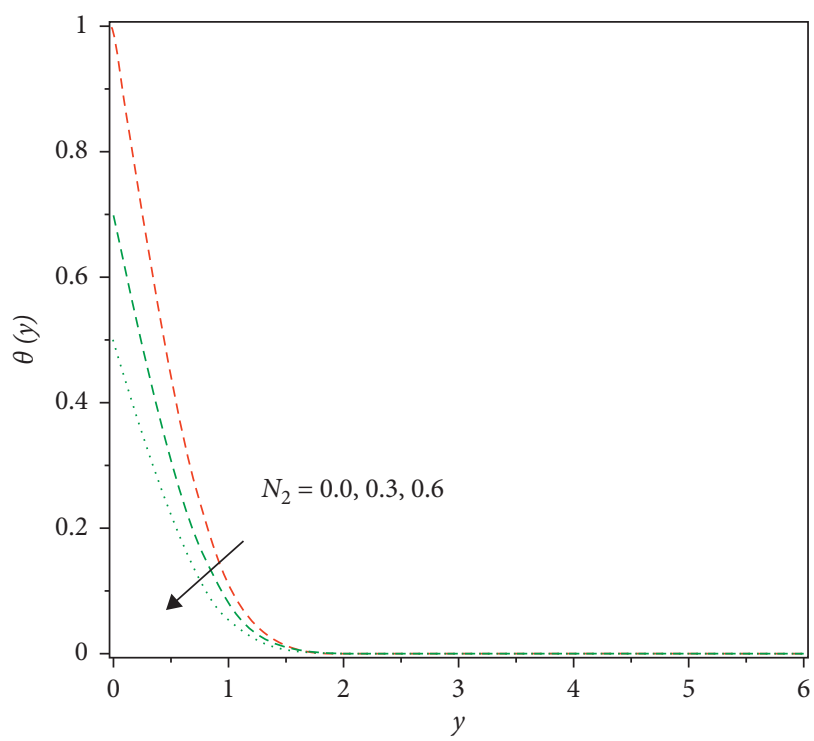

Figure 8: Influence of $N_{2}$ on $\theta$.

$$
\begin{aligned}
\chi_{o}(0) & =0, \\
\chi_{o}^{\prime}(0) & =1, \\
\chi_{o}^{\prime}(\infty) & =1, \\
\chi_{n}(0) & =0 \\
\chi_{n}^{\prime}(0) & =0, \\
\chi_{n}^{\prime}(\infty) & =0, \quad n=1,2,3, \ldots
\end{aligned}
$$

For equation (22), the series solution can also be explained in a similar way: 


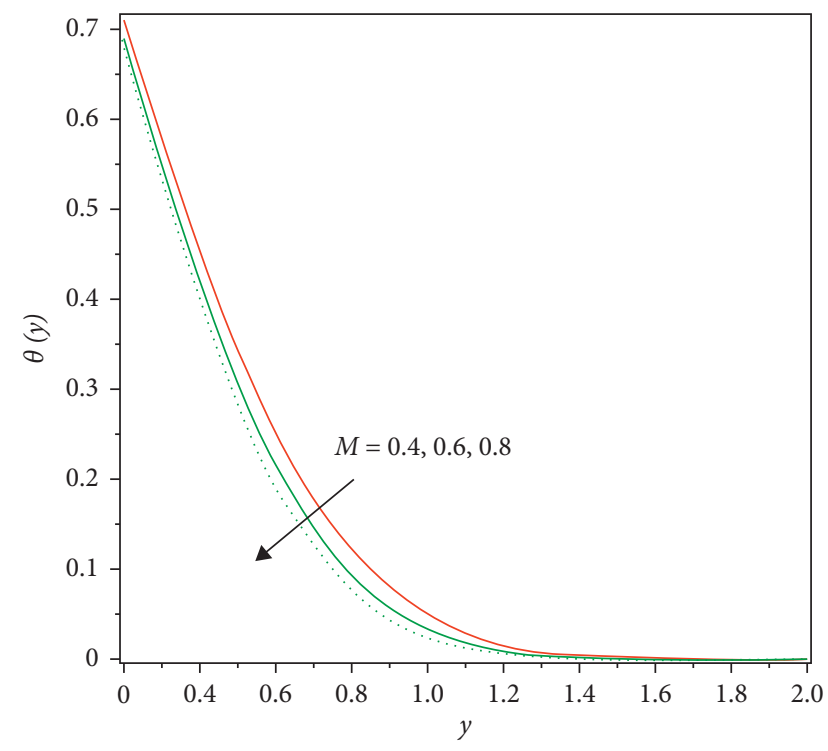

Figure 9: Influence of $M$ on $\theta$.

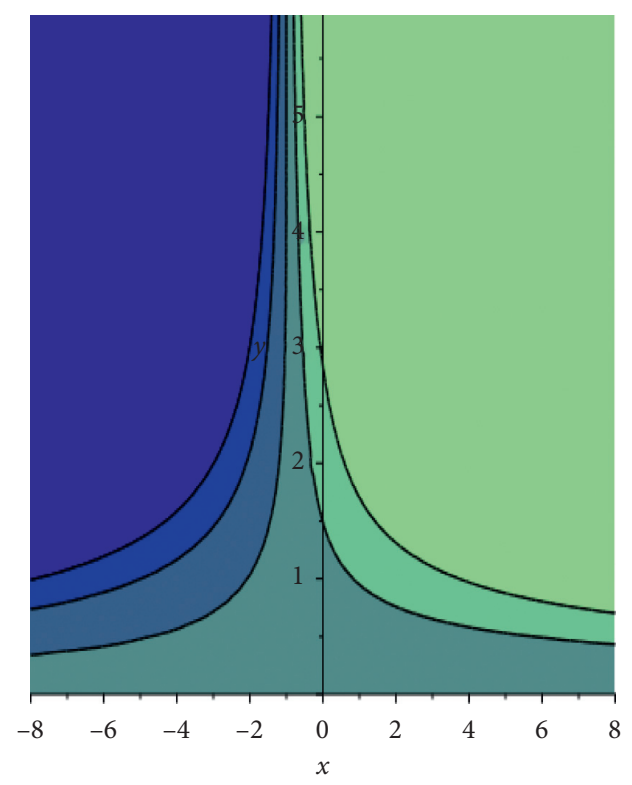

Figure 10: Stream lines for $M=0$.

$$
\theta_{1}(y)=\sum_{n=0}^{\infty}(i \Omega)^{n} \vartheta_{1 n}(y) .
$$

For minor values of $\Omega$ (considering the real part only), we obtain

$$
\theta_{1}(y)=\vartheta_{10}(y)-\Omega^{2} \vartheta_{12}(y)+\Omega^{4} \vartheta_{14}(y) .
$$

We have observed that $\vartheta_{10}(y)=\theta_{0}(y)$, and solving $\theta_{0}(y)$ by direct integration, we obtain

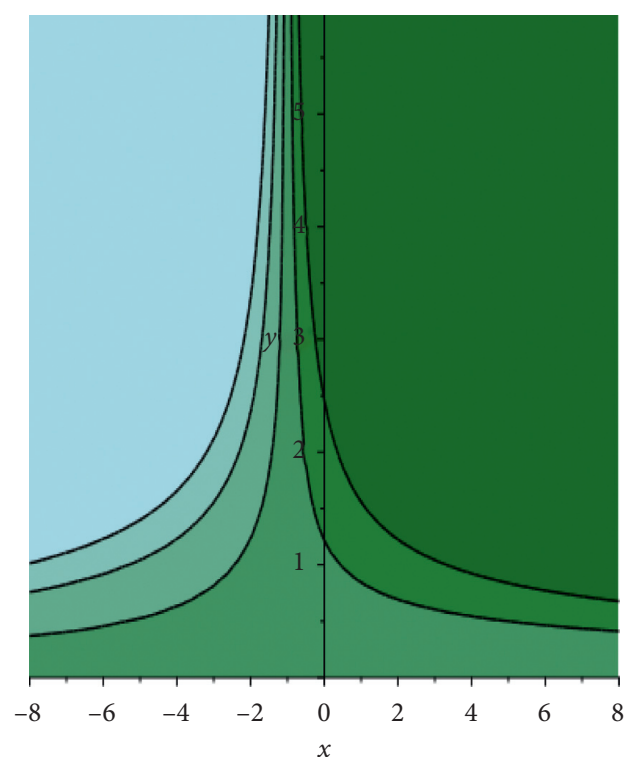

FIGURE 11: Stream lines for $M=0.3$.

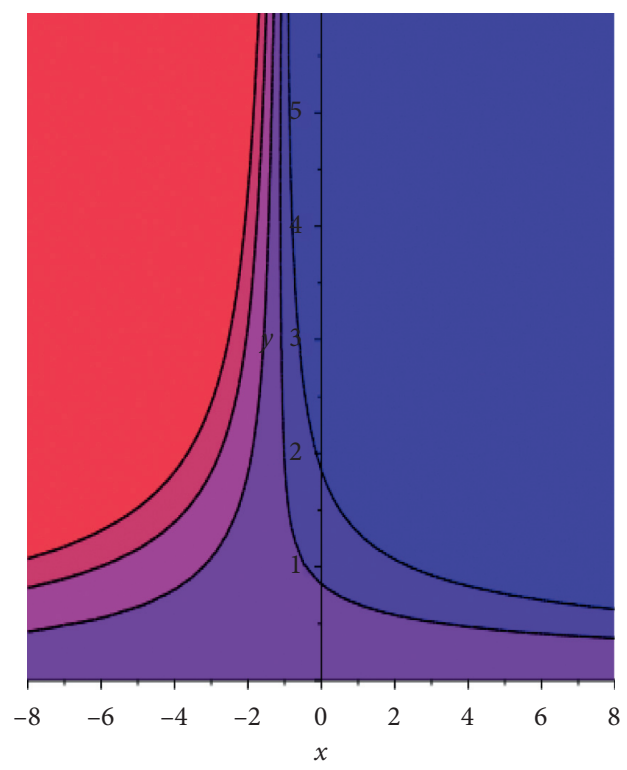

FigURE 12: Stream lines for $M=0.5$.

$$
\begin{aligned}
\theta_{0}(y) & =\frac{J_{n f}(\infty, P r)-J_{n f}(y, P r)}{J_{n f}(\infty, P r)}, \\
J_{n f}(y, \operatorname{Pr}) & =\int_{0}^{y} \operatorname{Exp}\left(-\operatorname{Pr} \frac{k_{f}}{k_{n f}} \frac{\left(\rho C_{p}\right)_{n f}}{\left(\rho C_{p}\right)_{f}} \int_{0}^{s} f(\eta) \mathrm{d} \eta\right) \mathrm{d} s .
\end{aligned}
$$

Finally, the series form solution of the temperature equation (22) becomes 


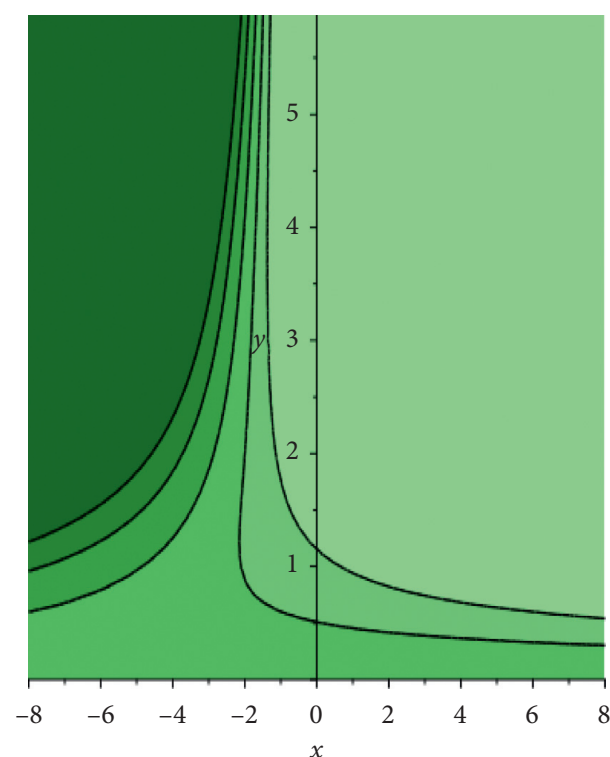

Figure 13: Stream lines for $M=0.7$.

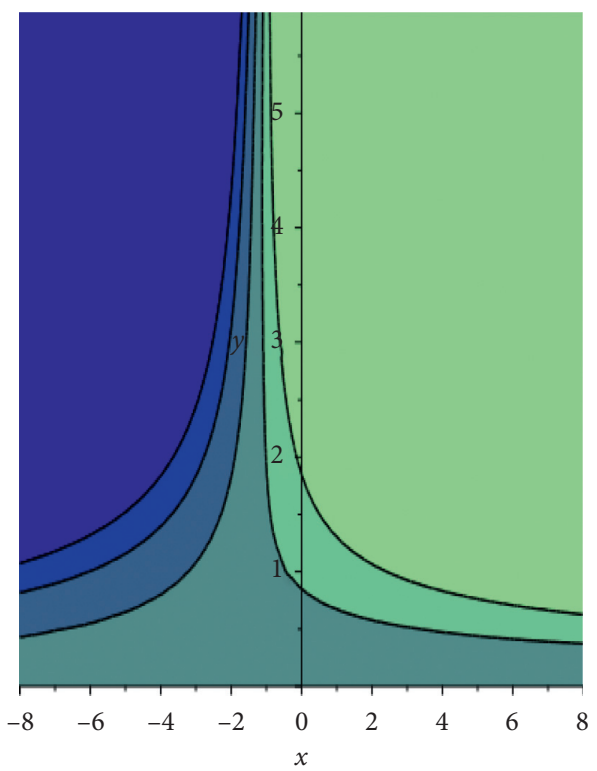

Figure 14: Stream lines for $\beta=0$.

$$
\begin{aligned}
\frac{1}{\operatorname{pr}} \frac{k_{n f}}{k_{f}} \vartheta_{1 n+}^{\prime \prime} \frac{\left(\rho C_{p}\right)_{n f}}{\left(\rho C_{p}\right)_{f}}\left(f \vartheta_{1 n}^{\prime}-\vartheta_{1(n-1)}\right) & =0, \\
\vartheta_{1 n}(0) & =1, \\
\vartheta_{1 n}(\infty) & =0, \quad n=1,2,3, \ldots
\end{aligned}
$$

Thermophysical properties of base fluid and nanoparticle are composed by [21].

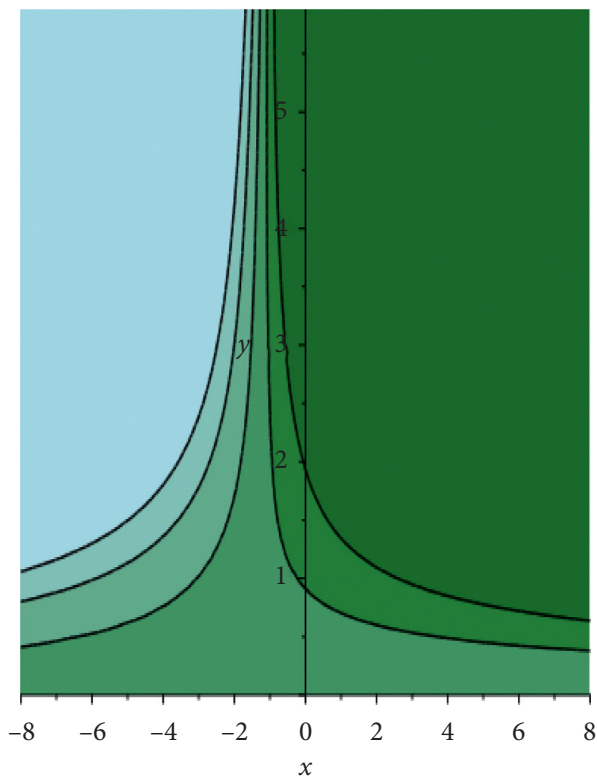

Figure 15: Stream lines for $\beta=1$.

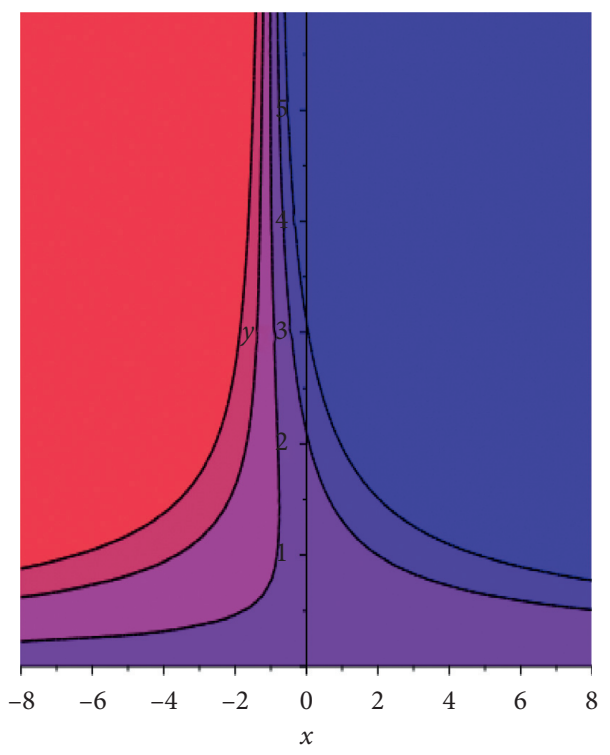

FIgURE 16: Stream lines for $\beta=2$.

\section{Discussion and Results}

The problem is solved by a mathematical technique such as bvp4c method in Matlab and maple and expresses the results by various parameter such as Hartmann number $M$, Casson parameter $\beta$, slip parameter $N_{1}$, and thermal slip parameter $\mathrm{N}_{2}$. We have illuminated graphically the behavior of flow parameters. Figures 2-7 exposed the velocity profiles commonly, and the nanofluid flow on the vacillating plate is operated through the mutual action of free stream velocity and magnetic field. At the plate surface, the nanofluid velocity is zero and rises slowly till it achieves the free stream 


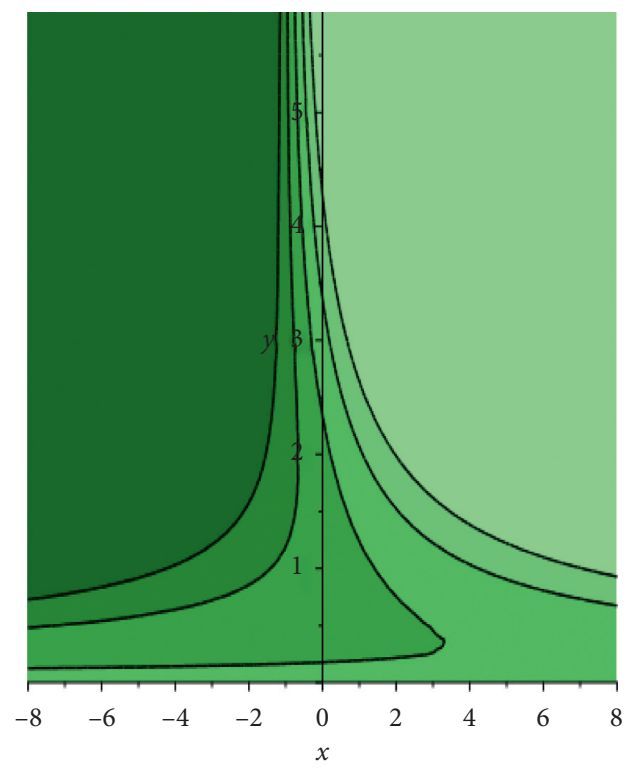

Figure 17: Stream lines for $\beta=3$.

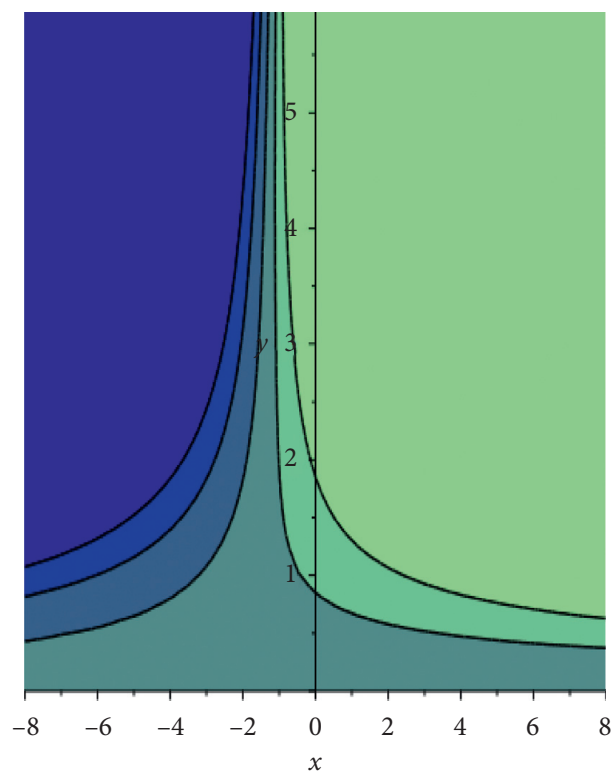

Figure 18: Stream lines for $N_{1}=0$.

value, satisfying the given boundary conditions. Figure 2 expresses the action of the velocity gradient $\left(F(y), F^{\prime}(y), F^{\prime \prime}(y)\right)$, which is described for $M=10^{-7}$ and $\beta=0.5$. Figure 3 shows the impact of Hartmann number $M$ on the velocity profile. When $M$ rises, then the velocity field declines and the viscosity of the boundary layer increases. On the fluid in the boundary layer, a resistive nature force produced by a magnetic field drops the motion of the fluid and the existing phenomena arise when it can describe the conductive fluid. Hence, lastly, it is expected that the magnetic field is utilized to curb boundary layer departure. Figure 4 demonstrates the effect of slip parameter $N_{1}$ on the velocity field. When $N_{1}$ rises, the velocity profile

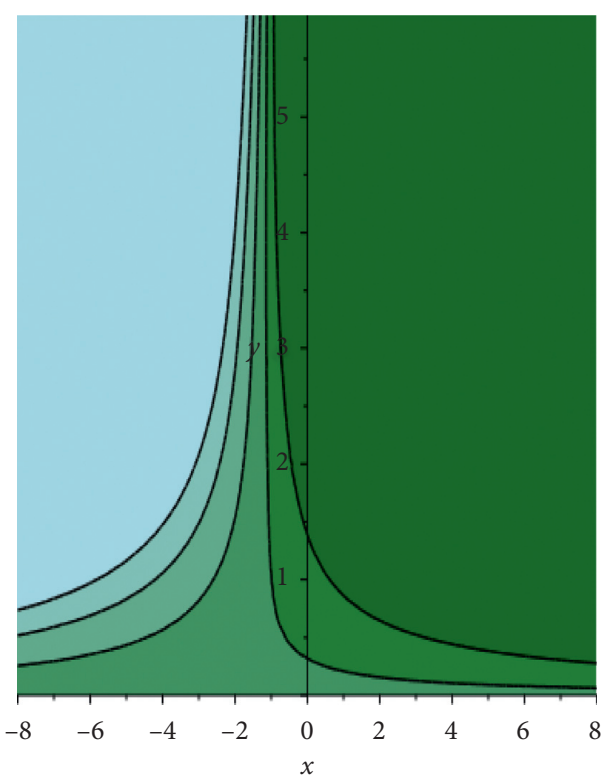

Figure 19: Stream lines for $N_{1}=0.5$.

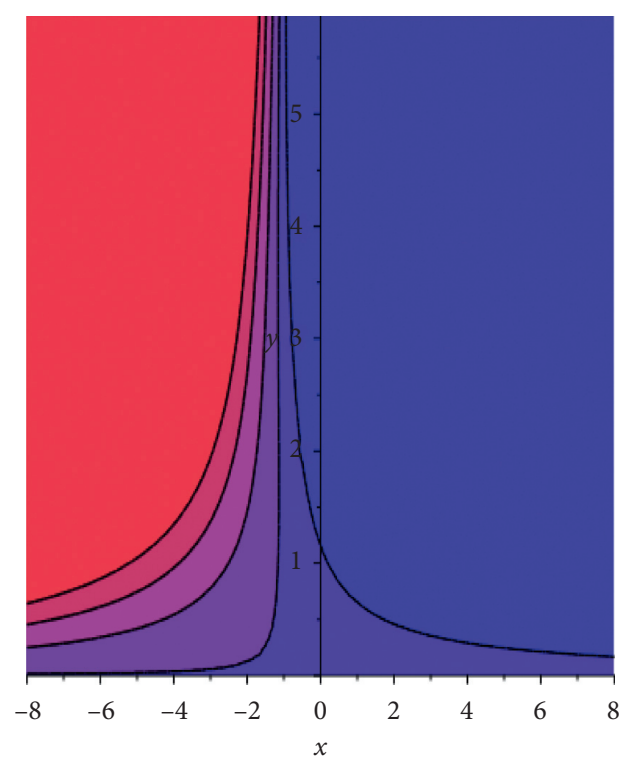

Figure 20: Stream lines for $N_{1}=1.0$.

enhances and the boundary layer declines. Figure 5 explored the effect of Casson parameter $\beta$ on the velocity profile. When Casson parameter $\beta$ increases, then the velocity field increases and the thickness of the boundary layer declines. On the other way, for Casson fluid, it is observed that the velocity boundary layer thickness is greater as compared to that of Newtonian fluid. Figures 6 and 7 expose the effects of the velocity profile $G^{\prime}(y)$ rises and the boundary layer drops when the values of Casson parameter $\beta$ and Hartmann number $M$ increases. Figures 8 and 9 show the temperature profiles $\theta(y)$ when $\operatorname{Pr}=6.2$; then, choose the values of thermal slip parameter $N_{2}$ and Hartmann number $M$. Thermal slip and hartmann number decrease the fluid 


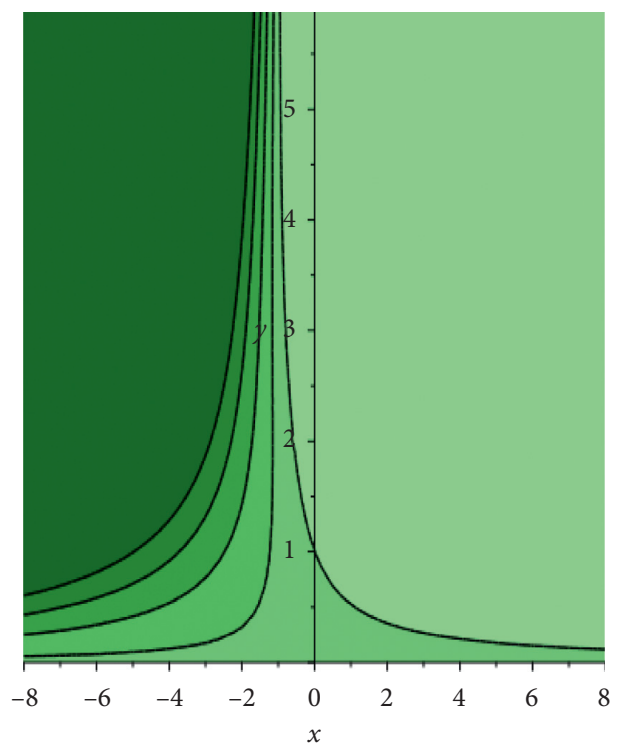

Figure 21: Stream lines for $N_{1}=1.5$.

TABle 1: Effects of $N_{1}, M$, and $\beta$ on skin friction.

\begin{tabular}{cccc}
\hline$N_{1}$ & $M$ & $\beta$ & $1 / 2 C_{f} R_{e}=F^{\prime}(0)+F^{\prime \prime}(0)$ \\
\hline 0.1 & 0.1 & 0.1 & -0.422760 \\
0.2 & & & -0.406519 \\
0.3 & & & -0.390821 \\
0.4 & & & -0.375770 \\
& 0.1 & & -0.422760 \\
& 0.4 & & -0.433007 \\
& 0.7 & & -0.4546469 \\
& 1.0 & 0.1 & -0.474569 \\
& & 0.11 & -0.422760 \\
& & 0.12 & -0.440139 \\
& & 0.13 & -0.456559 \\
& & & -0.472115 \\
\hline
\end{tabular}

TAble 2: Effects of $\gamma$ and Pr on Nusselt number.

\begin{tabular}{lcc}
\hline$N_{2}$ & $\varphi$ & $-\theta(\eta)$ \\
\hline 0.1 & 0.1 & 0.664914 \\
0.12 & & 0.821894 \\
0.14 & & 1.081942 \\
0.1 & 0.1 & 0.664914 \\
& 0.2 & 0.856256 \\
& 0.3 & 0.887956 \\
\hline
\end{tabular}

temperature. The boundary layer drops, and the temperature gradient at the surface also decreases. Physically, the momentum thickness and thermal boundary layer are functioned by Prandtl number. Low Prandtl number fluids have a greater rate of heat conduction; thus, heat can spread faster than for higher Pr fluid. Figures 10-21 demonstrate the effect of $M, \beta$, and $N_{1}$ on the stream line. Table 1 is made to examine the impact of $M$ and $\gamma$ on Skin friction; when the slip parameter $N_{1}$ rises, then the Skin friction enhances; when the Hartmann number $M$ increases, then Skin friction declines; and when Casson parameter increases, then the Skin friction also drops. Table 2 is made to explore the effect of $\operatorname{Pr}$ and $\gamma$ on Nusselt number; when thermal slip parameter $N_{1}$ and volume friction $\varphi$ increases, then the Nusselt number enhances.

\section{Conclusion}

In this section, we demonstrate the MHD oblique stagnation point flow of nanofluid to an oscillatory plate which contains copper $(\mathrm{Cu})$ as nanoparticle within the base fluid water. Also, consider the effect of thermal jump and velocity slip. The resulting opinions are worth citing:

Because it is perceived at a variant distance from the plate, and the behavior of angular velocity increases by rising volume friction parameter and slip parameter.

The heat transfer rate declines at the surface with rising Hartmann number, whereas it rises with raising values of nanoparticle volume fraction and thermal slip parameter. The stagnation point and zero skin friction depend on.

By expanding the Hartmann number and thermal stratification, the thermal boundary layer is dejected.

\section{Nomenclature}

\section{Symbols; Significance and Dimensions-Dimensionless}

$\bar{x}, \bar{y}: \quad$ Spatial coordinates $[\mathrm{L}]-x, y$

$\bar{p}: \quad$ Pressure field $\left[\mathrm{ML} / \mathrm{T}^{2}\right]-P$

$\bar{u}, \bar{v}: \quad$ Velocity components $[\mathrm{L} / \mathrm{T}]-u, v$

$\gamma: \quad$ Free stream parameter

$\bar{f}(\bar{y}): \quad$ Ordinary component of the stream $-F(y)$

$\bar{g}(\bar{y}): \quad$ Shear component of flow- $G(y)$

$\bar{\psi}: \quad$ Tributary function $\left[\mathrm{L}^{2} / \mathrm{T}\right]-\psi$

M: $\quad$ Hartmann number

T: $\quad$ Temperature field $[\mathrm{K}]-\theta(y)$

$N_{1}$ : $\quad$ Velocity slip parameter

$\mathrm{N}_{2}$ : Thermal slip parameter

$\beta$ : $\quad$ Casson parameter

$R e_{x}: \quad$ Reynold number

$\rho_{s}, \rho_{f}$ : Thickness of solid fraction and base fluid $\left[\mathrm{M} / \mathrm{L}^{3}\right]$

$\rho_{n f}: \quad$ Density of nanofluids

$\mu_{s}, \mu_{f}: \quad$ Dynamic thickness of solid fraction and base fluid $[\mathrm{M} / \mathrm{LT}]$

$\mu_{n f}: \quad$ Dynamic thickness of nanofluid

$v_{n f}: \quad$ Kinematic thickness of nanofluid

$v_{s}, v_{f}$ : Kinematic thickness of solid fraction and base fluid $\left[\mathrm{L}^{2} / \mathrm{T}\right]$

$\alpha_{n f}: \quad$ Thermal diffusivity of nanofluid

$k_{n f}$ : Thermal diffusivity of base fluid and solid fraction

$\sigma_{n f}: \quad$ Electrical conductivity of nanofluids

$\sigma_{f}, \sigma_{s}$ : Electrical conductivity of solid fraction and base fluid

$\alpha_{f}, \alpha_{s}:$ Thermal diffusivity of base fluid and solid fraction $\left(\rho C_{p}\right)_{n f}$ : Heat capacity of nanofluids 
$k_{f}, k_{s}: \quad$ Thermal conductivity of base fluid and nanoparticles $\left[\mathrm{ML} / \mathrm{T}^{3} \mathrm{~K}\right]$.

\section{Data Availability}

No data were used to support this study.

\section{Conflicts of Interest}

The authors declare that they have no conflicts of interest.

\section{References}

[1] S. U. Choi and J. A. Eastman, Enhancing Thermal Conductivity of Fluids with Nanoparticles (No. ANL/MSD/CP-84938), Argonne National Lab, Lemont, IL, USA, 1995.

[2] I. Khan, S. Fatima, M. Y. Malik, and T. Salahuddin, "Exponentially varying viscosity of magnetohydrodynamic mixed convection eyring-powell nanofluid flow over an inclined surface," Results in Physics, vol. 8, pp. 1194-1203, 2018.

[3] M. Turkyilmazoglu, "Free and circular jets cooled by single phase nanofluids," European Journal of Mechanics-B/Fluids, vol. 76, pp. 1-6, 2019.

[4] T. K. Nguyen, A. Saidizad, M. Jafaryar et al., "Influence of various shapes of $\mathrm{CuO}$ nanomaterial on nanofluid forced convection within a sinusoidal channel with obstacles," Chemical Engineering Research and Design, vol. 146, pp. 478-485, 2019.

[5] T. K. Nguyen, F. A. Soomro, J. A. Ali, R. U. Haq, M. Sheikholeslami, and A. Shafee, "Heat transfer of ethylene glycol- $\mathrm{Fe}_{3} \mathrm{O}_{4}$ nanofluid enclosed by curved porous cavity including electric field," Physica A: Statistical Mechanics and Its Applications, vol. 550, Article ID 123945, 2019.

[6] T. Nguyen-Thoi, M. Sheikholeslami, M. Hamid, R.-U. Haq, and A. Shafee, "CVFEM modeling for nanofluid behavior involving non-equilibrium model and lorentz effect in appearance of radiation," Physica A: Statistical Mechanics and Its Applications, vol. 534, Article ID 122154, 2019.

[7] R. Mehmood, R. Tabassum, O. Pourmehran, and D. D. Ganji, "Crosswise stream of hydrogen-oxide $\left(\mathrm{H}_{2} \mathrm{O}\right)$ through a porous media containing copper nanoparticles," International Journal of Hydrogen Energy, vol. 43, no. 15, pp. 7562-7569, 2018.

[8] H. Park, S. J. Lee, and S. Y. Jung, "Effect of nanofluid formation methods on behaviors of boiling bubbles," International Journal of Heat and Mass Transfer, vol. 135, pp. 1312-1318, 2019.

[9] H. Jang, W. S. Lee, and J. Lee, "Rheological characteristics of non-newtonian GPTMS-SiO ${ }_{2}$ nanofluids," International Communications in Heat and Mass Transfer, vol. 106, pp. 38-45, 2019.

[10] M. J. Assael, K. D. Antoniadis, W. A. Wakeham, and X. Zhang, "Potential applications of nanofluids for heat transfer," International Journal of Heat and Mass Transfer, vol. 138, pp. 597-607, 2019.

[11] A. Zeiny, H. Jin, G. Lin, P. Song, and D. Wen, "Solar evaporation via nanofluids: a comparative study," Renewable Energy, vol. 122, pp. 443-454, 2018.

[12] A. Huminic, G. Huminic, C. Fleacă, F. Dumitrache, and I. Morjan, "Thermo-physical properties of water based lanthanum oxide nanofluid an experimental study," Journal of Molecular Liquids, vol. 287, Article ID 111013, 2019.
[13] S. Nadeem, A. U. Khan, and S. Saleem, "A comparative analysis on different nanofluid models for the oscillatory stagnation point flow," The European Physical Journal Plus, vol. 131, no. 8, p. 261, 2016.

[14] K. Hiemenz, "Die grenzschicht an einem in den gleichformigen flussigkeitsstrom eingetauchten geraden kreiszylinder," Dinglers Polytech, vol. 326, pp. 321-324, 1911.

[15] A. U. Khan, S. Saleem, S. Nadeem, and A. A. Alderremy, "Analysis of unsteady non-axisymmetric homann stagnation point flow of nanofluid and possible existence of multiple solutions," Physica A: Statistical Mechanics and its Applications, vol. 554, Article ID 123920, 2019.

[16] N. Abbas, M. Y. Malik, M. S. Alqarni, and S. Nadeem, "Study of three dimensional stagnation point flow of hybrid nanofluid over an isotropic slip surface," Physica A: Statistical Mechanics and Its Applications, vol. 554, Article ID 124020, 2020.

[17] A. Hussain, S. Afzal, R. Rizwana, and M. Y. Malik, "MHD stagnation point flow of a casson fluid with variable viscosity flowing past an extending/shrinking sheet with slip effects," Physica A: Statistical Mechanics and Its Applications, vol. 553, Article ID 124080, 2020.

[18] R. Mehmood, S. Rana, N. S. Akbar, and S. Nadeem, "Nonaligned stagnation point flow of radiating casson fluid over a stretching surface," Alexandria Engineering Journal, vol. 57, no. 2, pp. 939-946, 2018.

[19] S. Nadeem, R. Mehmood, and N. S. Akbar, "Optimized analytical solution for oblique flow of a casson-nano fluid with convective boundary conditions," International Journal of Thermal Sciences, vol. 78, pp. 90-100, 2014.

[20] J. Ahmed, M. Khan, and L. Ahmad, "Stagnation point flow of maxwell nanofluid over a permeable rotating disk with heat source/sink," Journal of Molecular Liquids, vol. 287, Article ID 110853, 2019.

[21] N. P. Moshkin, V. V. Pukhnachev, and Y. D. Bozhkov, "On the unsteady, stagnation point flow of a maxwell fluid in 2D," International Journal of Non-linear Mechanics, vol. 116, pp. 32-38, 2019.

[22] P. Weidman, "Hiemenz stagnation-point flow impinging on a uniformly rotating plate," European Journal of Mechanics-B/ Fluids, vol. 78, 2019.

[23] E. Azhar, Z. Iqbal, and E. N. Maraj, "Viscous dissipation performance on stagnation point flow of jeffrey fluid inspired by internal heat generation and chemical reaction," Thermal Science and Engineering Progress, vol. 13, Article ID 100377, 2019.

[24] N. Abbas, S. Saleem, S. Nadeem, A. A. Alderremy, and A. U. Khan, "On stagnation point flow of a micro polar nanofluid past a circular cylinder with velocity and thermal slip," Results in Physics, vol. 9, pp. 1224-1232, 2018.

[25] N. S. Akbar, Z. H. Khan, and S. Nadeem, "The combined effects of slip and convective boundary conditions on stagnation-point flow of cnt suspended nanofluid over a stretching sheet," Journal of Molecular Liquids, vol. 196, pp. 21-25, 2014.

[26] T. R. Mahapatra and S. Sidui, "Unsteady heat transfer in nonaxisymmetric homann stagnation-point flows towards a stretching/shrinking sheet," European Journal of Mechanics-B/Fluids, vol. 75, pp. 199-208, 2019.

[27] X. Zhan, Y. He, B. Shen, Z. Sun, T. Shi, and X. Li, "Removal of gas bubbles from highly viscous non-newtonian fluids using controlled vibration," Chemical Engineering Science, vol. 185, pp. 76-83, 2018. 
[28] N. Ijaz, A. Zeeshan, and M. M. Bhatti, "Peristaltic propulsion of particulate non-newtonian ree-eyring fluid in a duct through constant magnetic field," Alexandria Engineering Journal, vol. 57, no. 2, pp. 1055-1060, 2018.

[29] A. Hussain, S. Akbar, L. Sarwar, S. Nadeem, and Z. Iqbal, "Effect of time dependent viscosity and radiation efficacy on a non-newtonian fluid flow," Heliyon, vol. 5, no. 2, Article ID e01203, 2019.

[30] A. Hussain, S. Ghafoor, M. Y. Malik, and S. Jamal, "An exploration of viscosity models in the realm of kinetic theory of liquids originated fluids," Results in Physics, vol. 7, pp. 2352-2360, 2017.

[31] H. B. Da Veiga and J. Yang, "On the energy equality for solutions to newtonian and non-newtonian fluids," Nonlinear Analysis, vol. 185, pp. 388-402, 2019.

[32] K. C. Da Silva, I. De Jesus Da Silva, L. A. Calçada, and C. M. Scheid, "The effect of previous sedimentation on the filtration and mudcake properties of newtonian and nonnewtonian fluids," Powder Technology, vol. 346, pp. 9-16, 2019.

[33] X. Yang, Y. Liang, and W. Chen, "A fractal roughness model for the transport of fractional non-newtonian fluid in microtubes," Chaos, Solitons \& Fractals, vol. 126, pp. 236-241, 2019.

[34] J. Deteix and D. Yakoubi, "Shear rate projection schemes for non-newtonian fluids," Computer Methods in Applied Mechanics and Engineering, vol. 354, pp. 620-636, 2019.

[35] A. Shaheen and S. Nadeem, "Metachronal wave analysis for non-newtonian fluid inside a symmetrical channel with ciliated walls," Results in Physics, vol. 7, pp. 1536-1549, 2017.

[36] A. Shaheen and S. Nadeem, "Metachronal wave analysis for non-newtonian fluid under thermophoresis and brownian motion effects," Results in Physics, vol. 7, pp. 2950-2957, 2017.

[37] S. Jegatheeswaran, A. Kazemzadeh, and F. Ein-Mozaffari, "Enhanced aeration efficiency in non-newtonian fluids using coaxial mixers: high-solidity ratio central impeller with an anchor," Chemical Engineering Journal, vol. 378, Article ID 122081, 2019.

[38] M. Abdolahzadeh, A. Tayebi, and P. Omidvar, "Mixing process of two-phase non-newtonian fluids in $2 \mathrm{D}$ using smoothed particle hydrodynamics," Computers \& Mathematics with Applications, vol. 78, no. 1, pp. 110-122, 2019.

[39] M. Dejam, "Dispersion in non-newtonian fluid flows in a conduit with porous walls," Chemical Engineering Science, vol. 189, pp. 296-310, 2018.

[40] Z. Wang, J. Zhang, S. A. Shirazi, and Y. Dou, "Experimental and numerical study of erosion in a non-newtonian hydraulic fracturing fluid," Wear, vol. 422, pp. 1-8, 2019. 